\title{
POPULATION AGING IN THE PEOPLE'S REPUBLIC OF CHINA*
}

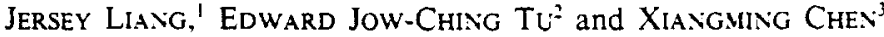 \\ 'Institute of Gerontology and Department of Medical Care Organization. School of Public Health. \\ The University of Michigan. Ann Arbor, MI 48109, "Center for Social and Demographic Analysis. \\ State University of New York at Albany. Albany. NY 12222 and ${ }^{3}$ Department of Sociology. \\ Duke University. Durham. NC 27706. U.S.A.
}

\begin{abstract}
This paper provides a factual assessment of China's population aging and its social and economic consequences. It is projected that China will have a substantially older population in the middle of the 21 st century. Major policy implications concerning old age support and health care have been examined.
\end{abstract}

Key words-demography, aging, policy, China

Accounting for nearly a quarter of the human race, China also has the largest population of older people (aged 65 and over) of any country in the world. The implementation of family planning policies has greatly accelerated the aging of its population. This paper aims to provide a factual assessment of this phenomenon and its social and economic consequences. In particular, based on the 1982 Chinese national census, a profile of the Chinese aged will be presented first. This encompasses the size and growth of the older population, life expectancy, causes of death, sex ratio, and dependency ratios. Furthermore, socioeconomic characteristics and the pattern of labor force participation of the Chinese elderly will be described. Second, the process of population aging will be examined within the context of demographic transition in China since 1949. The impact of the two baby booms during the last 30 years and the influences of population policies toward birth control upon population will be discussed. Third, social and economic implications of population aging in China will be examined. These include issues such as the newly emerged family structure, old age support, social mobility, long-term care, health care, and implications for future economic development.

\section{CHARACTERISTICS OF THE OLDER POPUlATION}

China has more than one billion people accounting for $22 \%$ of the world's population [1]. With a per capita gross national product of \$281 in 1982 (as compared with $\$ 12,820$ in the United States in 1981), China ranks in the bottom third of the developing nations $[2,3]$. In view of the fact that the percentage

*This is a revised version of a paper presented at the Annual Meeting of the Population Association of America. Boston. Massachusetts, March 28-30, 1985.

tDue to space limitations, a table of age compositions of selected countries is not included. It will be made available upon request from the authors. aged 65 and over in the world was 5.8 in 1980 . China has a relatively young population. In 1953, about 25 million persons, $4.4 \%$ of the total population in China, were of age 65 and over. This age group grew to over 49 million persons in 1982, accounting for $4.9 \%$ of China's population (Table 1). If one defines old age as 60 years of age or older, China had an older population of about 42 million people, $7.3 \%$ of the total population in 1953 . This group numbered 76.6 million persons or $7.6 \%$ of the total population in 1982. Between 1953 and 1982, the 60 and over population grew at an annual rate of $2.14 \%$ while the total population increased at a rate of $2 \%$ per year.

Of the total population aged 60 and over in 1982. $35.7 \%$ were 60 to 64 years old; $27.7 \%$ were 65 to 69 years old; $18.7 \%$ were 70 to 74 years of age; $11.3 \%$ were 75 to 79 years old; and $6.6 \%$ were 80 years of age or older. In terms of the age composition of the 60-and-over population, China clearly resembles developing countries although it has a higher proportion of older people than any other developing Asian, African, or Latin American nation [4]. In contrast, developed countries such as Sweden, United States, and Japan have higher proportions of 70 -and-over and 80-and-over populationst.

Life expectancy in China has increased substantially since 1949 (Table 2). Life expectancy at birth was about 35 years before 1949. According to Coale [5], life expectancy at birth in 1953-1964 was 42.2 years for males and 45.6 years for females. In 1964-1982, it rose to 61.6 years for males and 63.2 for females. Based on the 1982 census, the 1981 life expectancy at birth in China was 67.9 years; 66.4 years for males and 69.4 for females. At 65 , life expectancy is estimated to be 13.6 years. At this age, females are expected to outlive males by 2.16 years. With a median age at death of 67.5 years, the three leading causes of death are heart disease, cerebrovascular diseases, and malignant neoplasms, reflecting a pattern of mortalities similar to that of an aging population. This pattern also represents a dramatic shift in causes of death during the past three decades. Respiratory diseases, acute infectious dis- 
Table 1. Age structures of China in 1953. 1964, and 1982

\begin{tabular}{|c|c|c|c|c|c|c|}
\hline \multirow[b]{2}{*}{ Age } & \multicolumn{2}{|c|}{1953} & \multicolumn{2}{|c|}{1964} & \multicolumn{2}{|c|}{1982} \\
\hline & $\begin{array}{l}\text { Numbers } \\
\text { in } 1000\end{array}$ & $\%$ & $\begin{array}{l}\text { Numbers } \\
\text { in } 1000\end{array}$ & $\%$ & $\begin{array}{l}\text { Numbers } \\
\text { in } 1000\end{array}$ & $\because \circ$ \\
\hline $0-14$ & 206.845 & 35.67 & 281.650 & 40.53 & 337.251 & 33.45 \\
\hline $15-64$ & 347.558 & 59.94 & 388.608 & 55.92 & 621.506 & 61.65 \\
\hline 65 and over & 25,401 & 4.38 & 24,687 & 3.55 & 49.366 & 4.39 \\
\hline Total & 579.804 & 100.00 & 694.944 & 100.00 & 1.008 .123 & 100.00 \\
\hline 60 and over & 42,142 & 7.27 & 42.427 & 6.10 & 76,749 & 7.61 \\
\hline
\end{tabular}

Source: Coale A. J. Rapid Population Change in China. 1952-1982. National Academy Press, Washington, D.C., 1984.

Table 2. Life expectancies by gender, China, 1953-64, 1964-82, and 1981

\begin{tabular}{|c|c|c|c|}
\hline Life expectancies & $\begin{array}{c}\text { Total } \\
\text { population }\end{array}$ & Male & Female \\
\hline \multicolumn{4}{|l|}{ Before $1949(a)$} \\
\hline Life expectancy at birth & 35.00 & - & - \\
\hline \multicolumn{4}{|l|}{$1953-64(b)$} \\
\hline Life expectancy at birth & - & 42.20 & 45.58 \\
\hline Life expectancy at 65 & - & 7.88 & 9.59 \\
\hline \multicolumn{4}{|l|}{$1964-82(b)$} \\
\hline Life expectancy at birth & - & 61.64 & 63.22 \\
\hline Life expectancy at 65 & - & 11.29 & 12.93 \\
\hline \multicolumn{4}{|l|}{$1981(a)$} \\
\hline Life expectancy at birth & 67.88 & 66.43 & 69.35 \\
\hline Life expectancy at 65 & 13.59 & 12.44 & 14.60 \\
\hline
\end{tabular}

eases, and tuberculosis were the three leading causes of death in 1957 [3, p. 17].

Among those 60 years of age and over, the sex ratio is 87 which is higher than those in the more developed countries but is lower than in other developing countries such as India and Singapore.* In China, old people exhibit a profile of marital statuses similar to those in other countries. Specially, some $70 \%$ of older men are married and about $25 \%$ are widowed. Only $2.5 \%$ of older men have never been married and $1.5 \%$ are divorced. For older women, some $40 \%$ of them are married while nearly $60 \%$ are widowed. Only $0.3 \%$ of older women have never been married and less than $0.5 \%$ of them are divorced. In comparison with developed countries, China has much lower rates of singlehood and divorce (Table 3 ).

The Chinese elderly generally have very little education. Nearly $80 \%$ of the aged are illiterate or semi-illiterate. This proportion is more than twice as much as that for the population 12 years of age or older (i.e. $32 \%$ ). Only some $5 \%$ of the elderly have an educational background equivalent to junior high school or more. There are substantial gender and urban vs rural differences in educational background. While $61 \%$ of elderly men are illiterate or semiilliterate, over $95 \%$ of older women belong to the same category. In addition, rural areas exhibit a rate

*Due to space limitations. a table presenting sex ratios for the old populations in selected countries is not included It will be made available upon request.

tA table describing the proportions of illiterate population in the PRC is available upon request. of illiteracy or semi-illiteracy of $82 \%$ which is much higher than its urban counterpart $(64 \%) . \dagger$

For employees of the government and the state or collective enterprises in China, the retirement age is 60 for men and 55 for women. Using this definition of older population, the labor force participation rate of older persons in 1982 was $26 \%$ [6]. That is, $43 \%$ of the men 60 years of age or over were still in the labor force whereas only $16 \%$ of women 55 years of age or older were. However, it should be noted that the state and collective sectors account for only $25 \%$ of the total labor force and for agriculture labor retirement is less likely to be a viable option. Consequently, the labor force participation rate for the old population is probably understated. According to the 1982 Chinese national census, the majority of older workers $(84.8 \%)$ were engaged in farming and fishing. In comparison with the total population, there are higher percentages of older people in occupations such as governmental administrators and business managers $(1.3 \%)$, business $(2.1 \%)$, service $(4.1 \%)$, and farming and fishing $(84.8 \%$; Table 4$)$.

\section{POPULATION AGING IN CHIYA}

Demographers have long studied the process of population aging $[7,8]$. It has been demonstrated that population aging is essentially due to declines in fertility. Mortality declines in general have little effect on the age structure, and the few effects actually observed produce younger age structures. This is because typical improvements in health and medicine produce the greatest increases in survivorship among 
Table 3. Marital status of the older population (in percentage). China. 1982

\begin{tabular}{|c|c|c|c|c|c|c|c|c|}
\hline \multirow[b]{2}{*}{ Age } & \multicolumn{2}{|c|}{ Single } & \multicolumn{2}{|c|}{ Married } & \multicolumn{2}{|c|}{ Widowed } & \multicolumn{2}{|c|}{ Divorced } \\
\hline & Male & Female & Male & Female & Male & Female & Male & Female \\
\hline 15 and over & 32.7 & 24.2 & 61.9 & 65.5 & 4.5 & 10.0 & 0.9 & 0.3 \\
\hline $50-59$ & 3.0 & 0.2 & 86.5 & 82.2 & 8.5 & 17.2 & 2.0 & 0.5 \\
\hline $60-79$ & 2.5 & 0.3 & 70.6 & 44.2 & 25.3 & 55.1 & 1.6 & 0.4 \\
\hline 80 and over & 2.5 & 0.3 & 37.2 & 7.1 & 59.5 & 92.5 & 0.3 & 0.1 \\
\hline
\end{tabular}

Source: State Statistica! Bureau. Major Figures by 10 Percent Sampling Tabulation on the 1982 Population Census of the People"s Republic of China. Population Census Office. State Council and Department of Population Statistics. State Statistical Bureau. Beijing. 1983.

the young rather than the old. The effect of declining mortality is obscured by the much more powerful force of a falling birth rate occurring at the same time. This situation, however, may be changing. In countries where a life expectancy of 70 years or more has been reached, increases in longevity make the population older. Since there is little room to further improve survivorship of the young, any gains in longevity must concentrate at older ages [9]

With relatively high fertility and low mortality during most of the three and one-half decades since 1949, China has been a 'young' population. Children under age 15 constituted $36 \%$ of the total population in 1953 . This proportion climbed to over $40 \%$ in 1964 and then dropped to $33 \%$ in 1982 (Table 1). Meanwhile, the proportion of elderly persons aged 65 and over remained below $5 \%$ (i.e. $4.4 \%$ in $1953,3.6 \%$ in 1964 and $4.9 \%$ in 1982). Given the rapidly declining birth rate and relatively steady and low death rate, the population is expected to age rapidly from now on. This is especially true if the one-child family policy is successful.

Coale [10] has projected that, if China reaches zero population growth by the year 2000, about one quarter of the entire population will be over the age of 65 by 2035 . Keyfitz [11,12] made projections with an ultimate goal of a stationary population at 1.2 billion in the year 2000 . His projections assume births to be stabilized at 16.7 million each year and slightly falling mortality levels. These projections result in a favorable age structure until 2005. This is because the large recent cohorts of the 1920s and the 1980s are in retirement and in school respectively. After 2005, however, the fraction of elderly persons would begin to increase sharply. By 2040, when the last of the cohorts born between 1960 and 1975 reach 65 , the proportion of the aging population would reach its highest level at $20 \%$. The ratio of old people to labor force will first decline and after 2000 will rise as the baby boom cohorts of the 1960 s come up for retirement. The peak of the proportion of old people will occur in the 2040s.

However, both projections started with a total population of 910 million in 1975. Coale [10] assumed that the birth rate in 1975 was 24.6 per 1000 . falling to 19 per 1000 in 1980. Expectation of life at birth was about 65 years in $1975-1980$, and will rise to 70 years by 1995-2000. Keyfitz [11, 12], instead of using 1975 population as a base year. calculated 1980 population from 1975 population to complete projections from 1980 on. We feel that it is necessary to develop our own projections based on the 1982 adjusted census population [5, pp. 78-80], since all previous projections were made before the 1982 census became available.

Before presenting our projections of China's population, a brief description of the changes in mortality, fertility, and population growth are in order. In China, the death rate declined from roughly 25.5 deaths per 1000 people in 1953 to 7.3 per 1000 in 1981 , with an interruption by an increase reaching a peak rate of 38.8 deaths per 1000 during the food crisis years of 1958-1961. Hence, the population transition in China started in 1962 when the crude death rate began its steady decline (Fig. 1). With the release of age structures from China's three censuses, Coale [5, p. 70] estimated the intercensal life expectancies. The expectation of life at birth was 42.2 years for males and 45.6 years for females in 1953-1964, and rose to 61.6 for males and 63.2 for females in 1964-1982. Mortality in the 1953-1964 intercensal period was high. The pattern for survival for 1964-1982 shows relatively low mortality for a developing country.

Between 1950 and 1982, the birth rate fell by $50 \%$. The decline, however, has not been smooth or steady. The birth rate has fluctuated sharply with changes in political upheavals and birth control programs. In

Table 4. Occupational distribution of the older population. China. 1982

\begin{tabular}{|c|c|c|c|c|}
\hline Occupations & $\begin{array}{c}\text { Older population } \\
\text { in labor force } \\
(\%)\end{array}$ & $\begin{array}{c}\text { Whole population } \\
\text { in labor force } \\
(\%)\end{array}$ & $\begin{array}{l}\text { Percentage of older people } \\
\text { in the specific occupation }\end{array}$ & $\begin{array}{l}\text { Males per female } \\
\text { for older workers }\end{array}$ \\
\hline $\begin{array}{l}\text { Professional and technician } \\
\text { Governmental or business managers } \\
\text { Clerical } \\
\text { Business } \\
\text { Service } \\
\text { Farming and fishing } \\
\text { Industrial and transportation workers } \\
\text { Total }\end{array}$ & $\begin{array}{r}2.00 \\
1.28 \\
0.49 \\
2.14 \\
4.13 \\
84.83 \\
5.11 \\
100.00\end{array}$ & $\begin{array}{r}5.07 \\
1.55 \\
1.30 \\
1.81 \\
2.20 \\
72.02 \\
15.96 \\
100.00\end{array}$ & $\begin{array}{l}1.82 \\
3.83 \\
1.75 \\
5.51 \\
8.74 \\
5.49 \\
1.49 \\
-\end{array}$ & $\begin{array}{l}3.3 \\
3.6 \\
3.5 \\
1.8 \\
2.1 \\
1.6 \\
2.4 \\
-\end{array}$ \\
\hline
\end{tabular}

Source: State Statistical Bureau. Major Figures by 10 Percent Sampling Tabulation on the 1982 Population Census of the People's Republic of China. Population Census Office. State Council and Department of Population Statistics. State Statistical Bureau. Beijizg. 1983. 


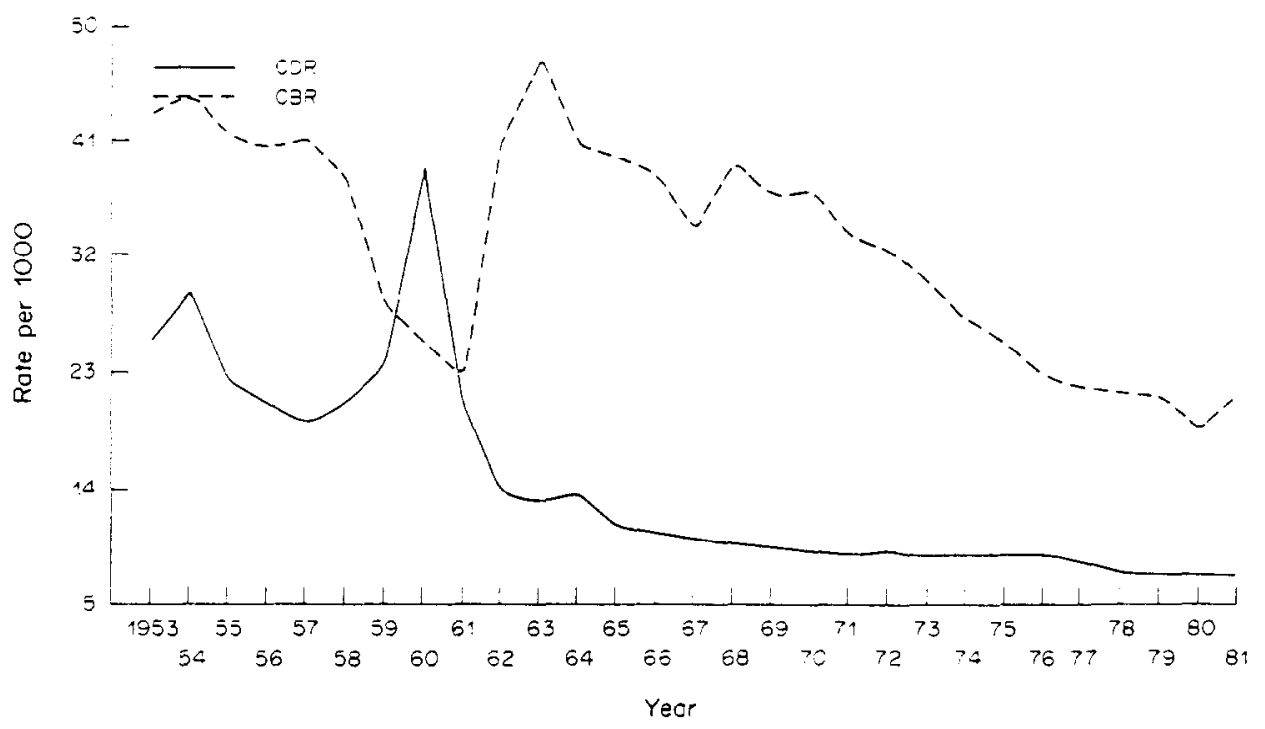

Fig. 1. Crude birth rates and crude death rates in China. 1953-1981.

1950 the rate was 41.3 births per 1000 people, a level that had prevailed for two decades. As a result of the Great Leap Forward in 1958-1959 and the famine of 1960-1961, the birth rate fell to around 25 per 1000 in 1959-1961. In the 1962 economic recovery, the birth rate bounced back and peaked at 44 per 1000 in 1963. During the Cultural Revolution of the late 1960 s, birth planning was abandoned. The birth rate fluctuated between 38 per 1000 in 1966 and 34 per 1000 in 1967 and rose to 39 per 1000 in 1968.

The full effect of organized population control began to be felt in the 1970 s. The birth planning campaign was launched with the slogan "Later, Longer, Fewer" in 1971. It was succeeded in 1979 by an even more restrictive program: the one-child campaign. By 1980 the birth rate had decreased to 18.5 per 1000. According to the 1982 census, there has been a recent increase in birth rate to 21.1 per 1000 population. This probably signals the start of a long-term trend as the large cohorts of people born during the $1960 \mathrm{~s}$ baby boom reach marriage and childbearing ages over the coming decade. Another factor recognized by Tien [13], was the boom in marriages in 1981 among those in their early twenties. This was made possible by the implementation of the 1980 Marriage Law. In general, the stable decline of fertility started from 1971 which is about nine years behind the steady decline of mortality.

Population aging is a by-product of population transition which is a long-term and presumably permanent change in the level of the birth and death rates of a population. Usually, mortality rates decline before fertility rates. Accordingly, an early effect of the transition is an increase in the rate of population growth. This is the stage in which China is right now. Because the death rate has declined so rapidly, the population is still growing even though fertility has begun to fall. The rate of natural- increase was 17.6 per 1000 people in 1953. After raising to 34.3 per 1000 in 1963, the rate has recently fallen, but only to 13 per 1000 in 1982. If this rate were maintained, the population in China would double itself every 53 years.

There was much debate in China about how many people the country's resources can support. In 1980 the Chinese Communist Party set the goal of 1.2 billion by the end of the 20th century. Furthermore, the government's goal is that the population should then be stationary. Within this goal and following Keyfitz's approach [11, 12], we made several assumptions. First, the decline to replacement-level fertility in China came in about 1982. Second, the death rate will continue to decline at the pace of the past few years. Third, the population in the year 2000 will be 1.2 billion. In order to achieve a stationary population of 1.2 billion, fertility must be below the replacement level before 2000 . One way to arrive at a stationary population is to have a constant number of births each year. In China, with its unique political organization, it appears to be able to control the annual number of births with considerable precision [12].

Our projections were based on the assumption that the annual number of births will be constant from now on. Although the assumption of immediate birth stationarity is unrealistic, this simplifies the projection considerably. It should be emphasized that our purpose here is merely to illustrate the consequences of fertility decline on age distribution. The life expectancy at birth over the next two generations will be 70.26 years from Model Life Tables [14]. If the mortality follows this course and an ultimate stationary population of 1.2 billion is assumed, then the corresponding annual births is 17.08 million. For the sake of simplicity we assumed that the decline to the constant number of births took place in 1982.

Our projections demonstrate a well-known phenomenon--demographic momentum, which is the tendency for population growth to continue beyond the time that replacement level fertility has been achieved. This is because of a relatively high concentration of people in the childbearing years. 


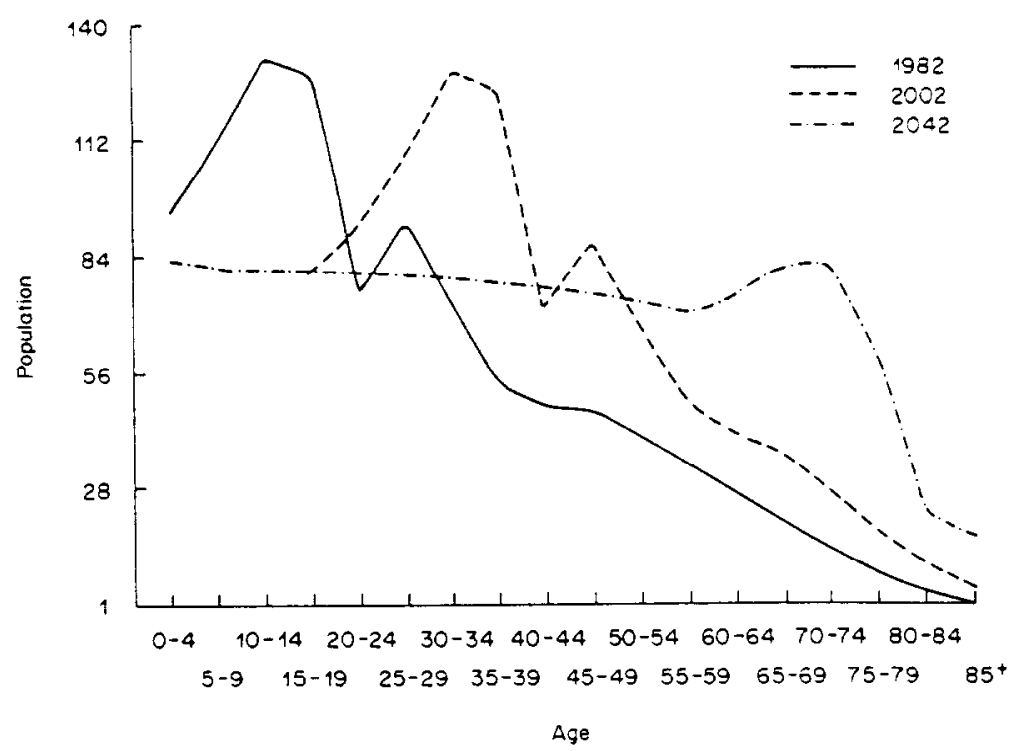

Fig. 2. Population projection for China, 1982-2042.

This is precisely what will happen in China. The large cohort made up of those born in the $1960 \mathrm{~s}$ and $1970 \mathrm{~s}$ will for many years continue to grow to 1.31 billion in 2032 and then decline to below 1.2 billion in 2072 . The hump for ages 5-19 of 1982 will appear at ages 25-39 in the year 2002 (Fig. 2) and so on; it will not disappear until 2062. This shifting peak is an inevitable feature of the Chinese population in the years to come, since the large cohorts in question are already born. The large numbers will be at young adult ages in 1997 and 2002, requiring very low fertility to maintain a low rate of increase. This very low fertility in turn will produce a very small proportion of young people in the population of subsequent years.

As the members of these large cohorts age and move through their working life, they will be followed by the small cohorts born after the annual number of births decline to 17.08 million. The immediate effects on the ratio of working force to the dependent population would be favorable. The fraction of the population in the working ages from 15 to 64 would continue to rise until 2007 (Fig. 3). After 2007, however, the proportion of 65 and over would begin to increase sharply. By 2042, when the last of the cohorts born between 1960 and 1977 reach 65 , the ratio of ages 65 and over to the working population would reach its highest level-34 elderly persons per 100 workers.

Our projections also indicate that the dependency ratio will decline from 62.2 in 1982 to the 40 s during 1992-2027 which is the 'golden period.' This ratio will then climb up to 66.0 in 2042 (Fig. 4). The golden

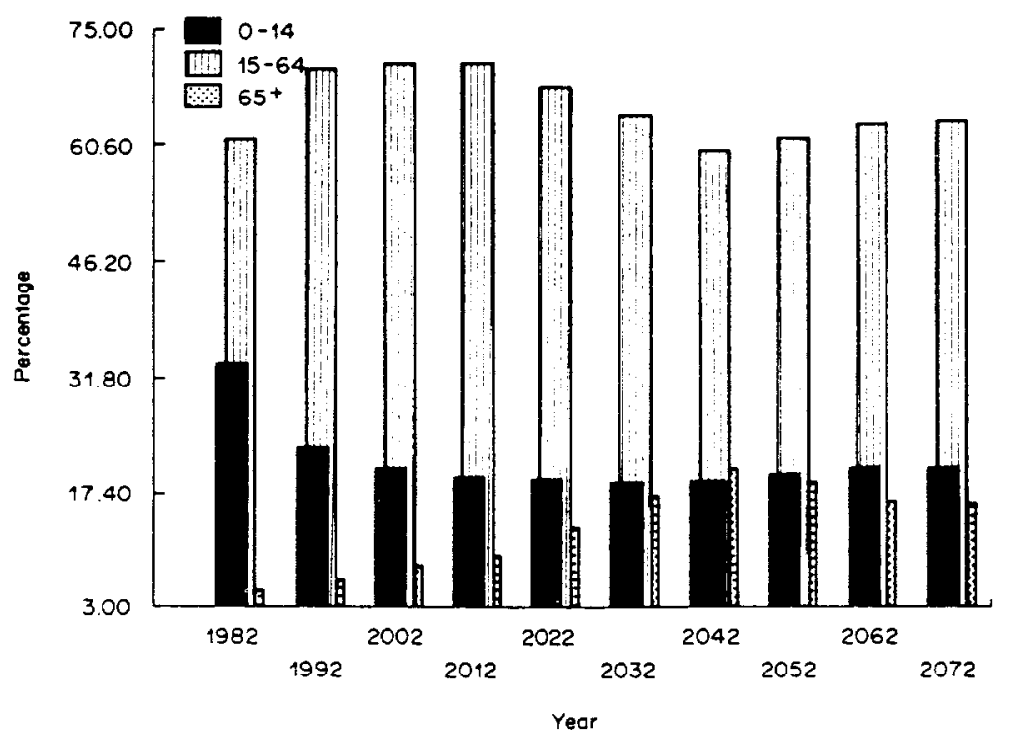

Fig. 3. Population age distribution in China, 1982-2072. 


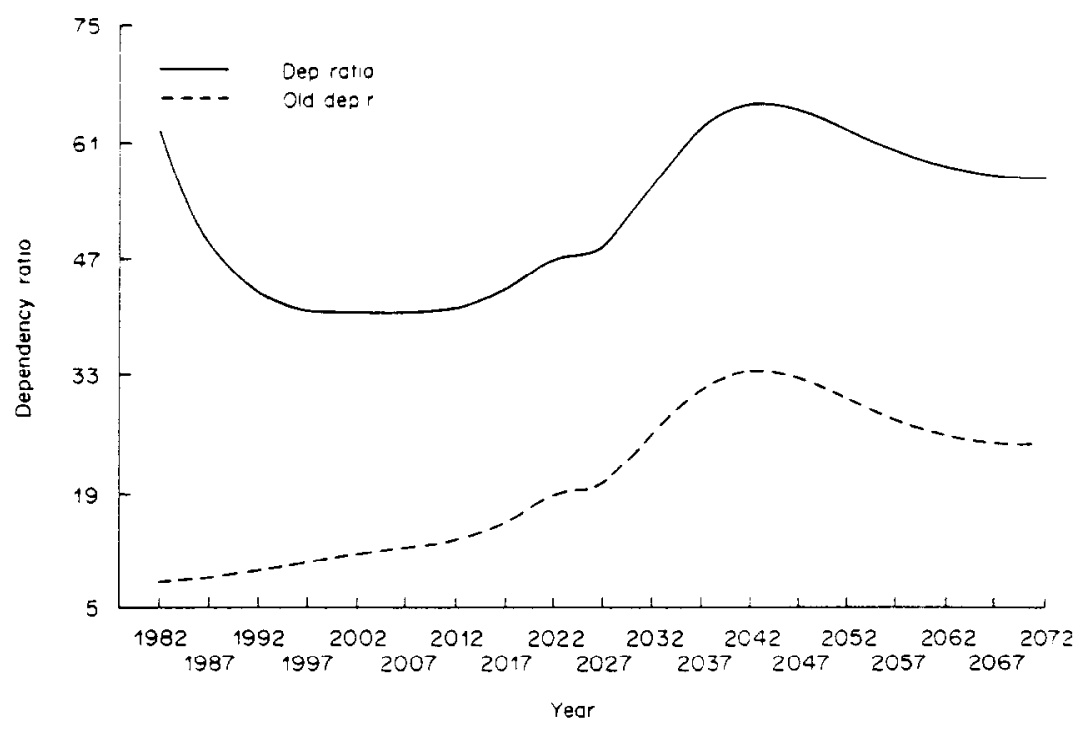

Fig. 4. Dependency ratio in China, 1982-2072.

period' is due to the large number of people born in the 1960 s entering the labor force while those leaving are the survivors of the much smaller cohorts of the 1920s. Eventually, the ratio of 65 and over to those aged 15-64 will rise continuously from 7.9 in 1982 to a peak of 34.1 in 2042 . In summary, the projections show that in the middle of the 21 st century a relatively small group of workers will be supporting a large group of elderly people.

One may argue that the decline in the number of young dependents resulting from lower fertility will offset the burden of an aging population to a significant extent. As pointed out by Sheppard and Rix [15], this would be true only if (1) there were person-for-person and a dollar-for-dollar trade off in expenditures for these two groups of dependents and (2) taxpayers were willing to pass on to the elderly the savings by having fewer children. Whereas there has been insufficient data concerning the validity of the second assumption, we know for fact that the first assumption is untrue in the United States. According to various estimates, between 1960 and 1979 the average government expenditure including Federal, state, and local funds on each elderly person was about three times the expenditure on each child. In 1983, the expenditure per child is less than one-tenth the expenditure per old person [16]. In view of this pattern, an increasingly large old age dependency ratio in China may become burdensome long before 2042.

\section{SOCIAL AND ECONOMIC IMPLICATIONS}

Population aging and its consequences have received some attention in China, although the control of population growth is clearly the major focus. It is generally recognized that population aging will not become a critical concern until the 2020 s $[17,18]$. There are some discussions of policies dealing with population aging in the future and several options have been suggested. These include: (1) raising the fertility rate to replacement level after the year 2000 .
(2) improving productivity, and (3) implementing a social security system [19]. There has been little research concerning the societal and economic consequences of fertility decline and population aging in China. In the following, we will briefly describe the Chinese systems of old age support and long-term and medical care. In addition, policy concerns will be identified.

\section{Old age support}

Old age support in China derives from two major sources: employment and family whereas community assistance plays a very limited role. One should note that old age support cannot be adequately addressed without taking into account the sharp disparities in financial well-being between rural and urban residents. The average income in urban areas is estimated to be more than two times as high as its rural counterpart [12, p. 47]. In 1981, urban income per capita was 500 yuan whereas rural income per capita was only 223 yuan [20].

In urban areas, pension programs are much better developed. There are two major programs. One covers employees in the state sector including government and party organizations, educational, cultural and scientific industrial enterprises. Although $80 \%$ of the urban workers are employed in the state sector, it only accounts for $21 \%$ of the total labor force [21]. Retirement age is 60 for men, 55 for female salaried employees, and 50 for female blue-collar workers. Furthermore. one needs to have at least 10 years' employment in the state sector to collect a pension. Pensions range from 60 to $100 \%$ of a worker's last wage depending on length of service and prior participation in revolutionary work. In addition to the pension payment, medical insurance benefits and other supplements received before retirement are included [22]. The administration and financing of pension benefits are the responsibility of individual employing institutions.

The other program. legislated in 1966. covers only workers of large urban collectives engaged in light 
industry and handicrafts. Emplovees of these collectives constitute less than $5 \%$ of China's total labor force [21]. Retirement benefits are less generous than those in the state sector. Benefit is payable on retirement after 20 years of work with eight years of continuous service and replaces $45-60 \%$ of preretirement wage. The collectives' plan does not include health insurance. Moreover, it should be noted that there is great variation in pension systems among collective enterprises.

Since 1979 , as a solution to the increasingly serious problem of unemployment, private enterprises have been allowed to exist. Employees in the private sector and those in small urban collectives are not covered by any public pension programs [22]. However, their number has expanded from 150,000 to 2.3 million between 1978 and 1983. Some provincial and municipal governments have encouraged government insurance companies to offer voluntary pension and health plans. The extent of such coverage is unknown.

Out of the 18 million persons of retirement age (males aged 60 and over; and females aged 55 and over) in urban areas, about 8 million or only some $45 \%$ received pensions in 1981 [24]. In 1983, the number of urban pensioners increased to 13 million [25]. Persons with no pensions are those who either left the labor force before a pension system was instituted at their work units or those having worked for less than the 10 years needed to be eligible for a pension. In addition, there are many people, mainly women, who never were members of the labor force. As mandated by the law, those older people are to be cared for by their children. Only the childless aged become the state's responsibility. The majority of old people in urban areas live in extended households with a grown child, usually a son.

For the Chinese elderly, family is the predominant mode of support. The rural labor force and workers in small urban collectives not covered by a pension program must depend on their adult children for old age support. More than $75 \%$ of the work force falls into this category. Consequently elderly men often continue to work even into their seventies by taking auxiliary jobs. In contrast, elderly women usually leave their full-time job completely after the birth of their first grandchild and devote their energies to household work. This partially accounts for the low labor force participation rate for older women. In 1980 , only 180,000 older people, or about $0.4 \%$ of all rural elderly, received old-age pensions [21]. Recently, there has been significant growth in that by the end of 1983. some 600,000 rural elderly people in over 9000 brigades were reported to have received pensions [26]. Nevertheless, it is uncertain whether such a trend will continue.

According to the Marriage Law, children have the duty to support and assist their aged parents. The 1980 Criminal Law explicitly states that violators of the Marriage Law are subject to criminal penalties. After the introduction of collective farming in the early 1950s, people were told that they could rely on the collective for 'five guarantees,' including food, clothing, medical care, housing, and burial expenses. However, it soon became apparent, such guarantees were to apply only to old people who had no pensions or grown sons to support them. Since daughters still generally marry out, old people in most rural areas can have living daughters and still qualify for "five guarantees. Local communities-neighborhood committees in cities and production brigades in rural communes-are responsible for the administration and financing of social welfare for the needy including the aged. In addition to the "five guarantees, it may also include helping the bedridden with daily chores, transportation, and a small cash allowance. In 1980, over three million old people, or some $6 \%$ of all elderly ( 65 and over) in China received five guarantees' [2!]

Our projection clearly indicates that China will have a substantially older population in the middle of the 21 st century. A primary policy concern is to provide adequate old age support in the years to come. Presently because of the small proportion of the older population, the needs of China's aged are being met by family initiatives and to some extent by state pensions. With the projected sharp increase in the number and proportion of old people and the decrease in average family size, the present system of old age support will be under severe strain. As a result of the one-child birth policy, the absence of siblings, the subsequent loss of in-laws. uncles. aunts, and the thinning out of extended relationships would remove a large number of branches from the family tree. This is most likely to weaken the family network which has been the backbone of old age support in China. The goals of family planning are clearly in conflict with the traditional family-based old age support system. To attain the objectives of both birth control and old age support. non-family based options for supporting the elderly such as the public old age pension systems in the developed countries, need to be explored.

In recent years, there has been an increase in the proportion of retired persons in the cities due to several factors. Strict control on migration to the large cities had the effect of increasing the proportion of old people, since migrants are typically young people. Compulsory retirement laws are also having an impact. Male factory workers and cadres retire at age 60 . Retirement age for their female counterparts is 55. Intellectuals may continue to work until age 65 . The large majority of the urban labor force is retired by age 60 . As a result, the number of retirees is increased substantially by including not only those 65 years of age and over, but also those between 60 and 64. As observed by Goldstein and Goldstein [24, p. $7]$, in the cities and towns males aged 60-64 years increase the total population of retired men by $65 \%$. For women, the adition of the 55-64 age group more than doubles the number of retired females.

There is also an explosion of young retirees (in their $50 \mathrm{~s}$ ) as a result of the ding -ti system, in which adult children are guaranteed jobs in their parent's place of work if the parent retires. With about four million young people entering labor force ages annually, there is a labor surplus in the urban areas. Most young people now expect to wait a full year after graduating from secondary school before being assigned a job [24]. This special inducement to early retirement was thought to be a useful means of dealing with unemployment among young adults. However, ding - $t i$ has been under official attack since 
a September 1983 State Council directive. It now appears to have been phased out in China.

There are, however, many exceptions to the mandatory retirement policy. Frequently, retirement at the mandatory age only occurs when both the employer and the employee find it economically expedient [4]. If an individual has a special technical skill or provides much needed political leadership, mandatory retirement is often not required. In some other situations exceptions can be made when an employee cannot afford a reduction in income due to heavy financial obligations. Moreover, some retirees have regular paid jobs and many are engaged in volunteer work.

As suggested by Spengler [26, p. 94], the economic well-being of the elderly depends on the old age dependency ratio and the proportion of working age population which is employed and contributing to old age support through pension and social security systems. These two conditions in turn depend upon how efficiently the economy functions. Despite the aging of the population, a manageable old age dependency ratio can be achieved if the retirement age is raised sufficiently. As indicated by our projection, given the current retirement age of 60 and assuming 17.08 million births per year, the ratio of retirees to workers was 13 to 100 in 1982 . This ratio can be maintained by raising the age of retirement to 64 in 2002. to 69 in 2022 and to a maximum of 74 in 2042. Thereafter the retirement age could be slowly lowered. Similar conclusions were reached by Keyfitz [12, p. 46].

As noted by Keyfitz [12, p. 46], there would certainly be objections to such a proposal. The major concern would be the unfavorable impact on upward mobility for the young. The recent substantial fertility decline in China can be viewed as a population wave which influences various parts of the economy especially those serving specific age groups. These include schooling. work and promotion, and retirement. Keyfitz [28] vividly illustrated the way that an increase in the number of older persons slows down upward mobility on the part of young people. He analyzed the extent that the age of promotion depends on the rate of population increase under different mortality schedules and other circumstances. The effect turns out to be substantial in that a change from $2 \%$ annual increase to stationary condition implies a delay in reaching the middle positions of the average factory office of 4.5 years. The aged would be perceived as holding on to the good jobs. This can he very divisive and may generate a lot of intergenerational conflicts. Given that the elderly must be provided for, and if the old age dependency ratio is high, a choice must be made between allowing the elderly to keep their jobs and supporting them with tax money.

Maintaining a high level of employment for the working age population is also critical to the economic well-being of the old. Unemployment in the working age population reduces the capacity of this population to contribute to the pension and social security funds. Moreover, unemployment of young workers may depress employment and income among older workers [26]. Currently, a major problem in China is unemployment among young people born in the 1960s who are entering the labor force in large numbers. Indeed, the ding - $t i$ system was instituted to alleviate the problem of unemployment. However. such a system can be very expensive and has only limited impact. This is because a shift of individuals from the labor force to the retiree category simultaneously decrease the number of contributors to the retirement-income stream and increases the number drawing upon this stream.

In 1979, the production responsibility system was introduced into the rural areas. This turned the collective management system to one of production contracts negotiated between the government and individual families. It has encouraged the cultivation of small private plots and raising of private livestock. Restrictions on the private sales of agricultural goods have been relaxed. On the other hand. in urban areas, private enterprises have been allowed to exist. Clearly, many more inflexibilities in the economy need to be eliminated in order to reduce unemployment. Hence a great flow of funds would be available for economic development as well as old age support.

It should be noted that the unemployment problem is likely to ease in the 1990s. Using data of the past 30 years (1952-1982), Chen [29] made projections of labor force participation in China for the period between 1982 and 1995 . The labor force entrants will decline by $6.5 \%$ per annum from 1989 to 1995 and $8.8 \%$ from 1992 to 1995 . The shrinking cohorts from the early 1970 s will cause a sharp drop in the number of laborers entering the labor force at age 18 in the early 1990 s.

\section{Long-term and medical care}

As a result of population aging, the demand for long-term care in China is expected to increase substantially. Currently, the majority of such care is provided by the family or volunteers in the community, whereas institutionalized care is reserved as the last resort. Nationally only 169,000 elderly people or $0.33 \%$ of the 65 and over population were institutionalized in 1984. In the urban areas, there were 684 social welfarc homes caring for some 22,000 elderly people [30]. In the rural areas, there were 11,000 homes for the aged which cared for some 147,000 older people [30, pp. 6 and 31]. Nevertheless, estimates of the institutionalized elderly in the countryside vary considerably. Some estimates were as high as 21,000 homes housing 241,000 elders in the rural areas [32]. Furthermore, as noted by Davis-Friedmann, the number of institutionalized has fluctuated greatly over the past 30 years as a function of government policies [4].

Another factor accounting for such a low rate of institutionalization is the relatively young age composition of the elderly population. In China the proportions of the aged population in the $75-79$ and 80 and over age groups are 11.2 and $6.6 \%$ respectively $[6$, p. 20]. The proportions in the U.S. are $12.5 \%(75-79$ age group) and $14.9 \%$ ( 80 and over age group). In view of the fact that the population in China will become older and sicker, and the average family size will be substantially reduced, the current system is unlikely to meet the increasing need for long-term care in the future. Alternative mechanisms 
for delivery long-term care, institutionalized as well as non-institutionalized, need to be explored.

According to Prescott and Jamison [33], the per capita health expenditure in China is relatively high for a country at its low per capita income level. In 1981 the health expenditure accounted for $3.3 \%$ of Gross Domestic Product per capita which is $25 \%$ greater than that would be predicted according to the pattern in other developing countries. Health care financing comes from three major sources: private outlays $(32 \%)$, labor insurance $(31 \%)$, and state budget expenditure $(30 \%)$. The residual $7 \%$ is financed by production brigades. As one of the most remarkable achievements of the Chinese health system. $70 \%$ of the total population is covered by various health insurances $[33$, p. 397].

Health insurances in China essentially take three forms: government health insurance, labor insurance, and rural cooperative insurance. Introduced in 1951, the Government Insurance Scheme provides free outpatient and inpatient services (excluding hospital meds) to government employees, college teachers, and college students. In general only primary members are covered and the dependents receive no benefit entitlements. This scheme is exclusively financed by the state budget. Workers and staff employed in state enterprises with more then 100 employees are insured by the Labor Insurance Scheme. It entitles primary members to free health care for life and their dependents to $50 \%$ reimbursement of health care costs. The labor insurance is financed by the enterprise with no individual prepayment by the employee. Implementation of the rural cooperative insurance system began in 1968 . Cooperative insurance schemes generally take the form of a prepaid medical insurance plan, organized at the production brigade level. Beneficiaries are entitled to free or substantially reimbursable services and drugs at the brigade health station and also at higher level referral units.

Unlike the health care system in the U.S., the Chinese system does not provide any special entitlement to the aged. Nevertheless, the increasing size of the clderly population will exert additional pressure on the health care system. This is further complicated by several factors. First, there are sharp disparities in hospital beds and health personnel distributed between the urban and rural areas. In 1980 there were 3.7 hospital beds per 1000 in urban areas but only 1.5 per 1000 in rural areas. The distribution of physicians is even more uneven with 2.4 per 1000 people in the urban areas and 0.5 per 1000 in the countryside [34]. Second, since 1980 the rural health system has undergone substantial changes whereas the urban system has remained intact. Given the general economic reforms, collective financing and popular support for the cooperative medical system have diminished. The proportion of the rural population protected by this system has declined by $50 \%$. People now have the option to pay more out of their own pockets for better medical services. The state also encourages and supports physicians to have private practices by setting up clinics or small-scale hospitals. More than 80,000 doctors are in private practice in China in 1985, an increase of more than $63 \%$ over the previous year.
These doctors are more profit-oriented and charge more for their services. This has serious implications in terms of the continuing education of the primary health workers, the barefoot doctors, and the increasing financial burden of illness on the peasants $[34$, p. 934]. Consequently, these reforms may have a negative effect on the elderly, since they will have to pay more. Those without pensions will be in an even more disadvantageous position.

\section{CONCLLSION}

The social and economic implications of China's aging population are manifold and intermingled with many other factors. A sensible analysis of these consequences requires a keen awareness of China's unique social, political, and demographic characteristics which include a centralized policy-making structure, a large rural population, and a fast growing private sector.

A major advantage derived from lowering fertility is that additional savings can be devoted to economic development. But in the long run, the decline in the proportion of young people will be offset by a large proportion of the elderly [35]. In addition, the phenomenon of population aging often coincides with other processes such as urbanization and increased industrialization. A substantial transformation of the occupational structure seems inevitable as the Chinese economy modernizes. Further economic growth will reduce the demand for the sizeable rural manual labor force. This major change in the economy, together with the accelerated pace of urbanization would create an urban population of six and seven hundred million sometime in the next century $[10, p$. 95].

More importantly, the design and implementation of policies on aging have and will continue to be centered around the relationship between the traditional family and the political state in China. The tension already in existence will mount over time as the current family planning program further chips away the cornerstone of the old age support. The state's capability in replacing part of the responsibility from the family hinges on how well the modernization program proceeds. The way in which these policies are formulated and carried out is crucial to the well-being of what will be about 200 million Chinese elderly by the middle of the $21 \mathrm{st}$ century. The aging-related policies and those addressing other concerns must be scrutinized carefully. Undoubtedly, China will have to make many difficult choices in order to meet the challenge of supporting a large aged population in the coming century.

Acknowledgements - The assistance provided by Joan Bennett, Nancy Fultz, Jorge F. Tapia, Diane Voss and Nancy Whitelaw is gratefully acknowledged. Debbie Davis. Friedmann. Barbara Logue. George Myers, Bill Parish. Alice Rossi, Gordon Streib, Judy Treas. Martin Whyte, and Amy Wilson have made many useful comments on earlier versions of this paper.

\section{REFERENCES}

1. Banister J. An analysis of recent data on the population of China. Populn Derl. Rer. 10, 241-271, 1984. 
2. World Bank Atlas. Population. Per Capita Product. and Growth Rates. World Bank, Washington. D.C. 1983

3. Jiang $Z$., Zhang $W$. and Zhu L. A preliminary examination of life expectancy in China. Ren Kou Yu Jing Ji (Popuin Econ.) 3, 14-17, 1984.

4. Davis-Freidmann D. Long Lires: Chinese Elderly and the Communist Rerolution. Harvard Lniversity Press. Cambridge, Mass., 1983

5. Coale A. J. Rapid Population Change in China. 1952-1982. National Academy Press. Washington. D.C., 1984.

6. Xu Q. Characteristics of the older population in our nation. She Hui (Society) 4, 19-24, 1984

7. Coale A. J. How the age distribution of a human population is determined. Cold Spring Harb. Symp quant. Biol. 23, 136-143, 1957.

8. Coale A. J. and Trussell T. J. "Roots" or how a population forgets its past. Can. Siud. Populn 8, 1-25. 1981.

9. Myers G. Mortality declines, life extension and population aging. Proceedings of Selected Papers of International Union for Scientific Study of Population. Manila, 1983.

10. Coale A. J. Population trends, policy, and studies in China. Popuin Derl. Rev. 7, 85-97. 1981

11. Keyfitz N. Population and Employment in China. IIASA working paper, wp-82-14, February, 1982

12. Keyfitz N. The population of China. Scient. Am. 250 , $38-47,1984$

13. Tien H. Y. Age at marriage in the People's Republic of China. The China Quarterly 93, 90-107, 1983.

14. Coale A. J. and Demney P. Regional Model Tables and Stable Populations. Princeton University Press, Princeton.

15. Sheppard H. L. and Rix S. E. The Graying of Working America: The Coming Crisis in Retirement-Age Policy. The Free Press, New York, 1977.

16. Preston S. H. Children and the elderly in the U.S Scient. Am. 251, 44 49, 1984.

17. Lin F. Forecasting the future population in China. Ren Kou Yan Jiu (Populn Res.) 2, 16-22, 1980.

18. Song J., Tian X.. Yu J. and Li G. Ren Ko Yu Ce He Ren Ko Kong Zhi (Population Forecast and Population Control). People's Publishing, Beijing, 1982.

19. Wang $N$. Issues related to policies concerning the control of population growth in China. Ren Kou Yan Jiu (Populn Res.) 2, 51-55, 1981 .
20. State Statistical Bureau. People's Rzpublic of China Statistical Yearboot of China. 1982. Economic Information and Agency. Hong Kong, 1982

21. Liu L. Mandatory retirement and other reforms pose new challenges tor China's government. Aging \& work 5. 119-133, 1982

22. International Policy Staff. Office of Policy, Social Security Administration. Social Security in the People's Republic of China (PRC). Linpublished mimeograph. 1985.

23. Whyte M. K and Parish W. L. Croun Life in Contemporary China. The University of Chicago Press. Chicago, 1984.

24. Goldstein $\mathrm{A}$. and Goldstein S. The challenge of an aging population in the People's Republic of China. Paper presented at the Annual lfeeting of the Population Association of Amcrica, Minneapolis. Minnesota, May 1984

25. Weltare benefits becoming common. Beijing Rer. 27, 13 . October 8. 1984.

26. Yuan J. Providing for the elderly in China. Paper presented at the XIIIth International Congress of Geron. tologr, New York City, July. 1985

27. Spengler J. J. Facing Zero Population Growth: Reactions and Interpretations, Past and Present. Duke University Press, Durham, N.C.. 1978.

28. Keyfitz $\mathrm{N}$. Population waves. In Population Dinamics (Edited by Greville T. N. E.). pp. 1-39. Academic Press. New York, 1972

29. Chen $X$. Unpublished calculations, 1985. (Obtainable from Dr X. Chen. Department of Sociology. Duke University, Durham, NC 27706, U.S.A.)

30. Tau L. Social problems related to population aging in our country. She Hui (Society) 4, 1--. 1984.

31. One hundred forty thousand Five-Guarantee elderly people have a secure old age. People's Daily, p. 2. January 31, 1984.

32. State Statistical Bureau Communique on fulfillment of China's 1984 economic and social devalopment plan. Beijing Rer. 28, 1-20, March 25. 1985

33. Prescott $N$. and Jamison D. T. Health sector finance in China. Wld Hlth Stat. Q. 37, 387-402. 1984

34. Hsiao W. C. Transformation of health care in China New Engl. J. Med. 310,932-936, 1984.

35. World Bank. World Development Report 1984. Oxford University Press. 1984 